\title{
Speculative Harbouring: Wading into Critical Pedagogy and Practices of Care
}

\author{
Susanne Pratt ${ }^{1}$ and Kate Johnston ${ }^{2}$ \\ ${ }^{1}$ University of Technology Sydney, Sydney, Australia and ${ }^{2}$ The University of Sydney, \\ Sydney, Australia
}

\section{Acknowledgements}

The walkshop and field guide were made possible with funding from the Sydney Environment Institution (SEI). The project also received in-kind support from the Faculty of Transdisciplinary Innovation at the University of Technology Sydney (UTS) and the Sustainable Fish Lab. The Sustainable Fish Lab was funded by an Australian Research Council Discovery Project grant (Prof Elspeth Probyn) and housed in the Department of Gender and Cultural Studies, The University of Sydney. We would also like to thank all of the people who took part in the walkshop: Natali Jane Pearson; Caitlin Fargher; Jamaya Masters; Bernadette Smith; Mark Elliot-Ranken; Kassandra Bossell; Joseph McDonald; Daren Shi Chi Leung; Kate Eager; Christine Winter; Louisa King; and Jakelin Troy. A further special thanks to Ross Coleman and Elder Uncle Mark for their expert guidance during the walkshop; and to Roxana Knittel for bringing everyone's pages together through her design of the field guide.

\begin{abstract}
This text explicates a particular pedagogical event-Speculative Harbouring-a postgraduate workshop in which students from different disciplines formed around concerns of how we might better care for, and with, urban harbours. The harbour we attended to is presently referred to as Blackwattle Bay, which is a site in Eora Nation, Sydney, Australia currently undergoing significant redevelopment. The purpose of the workshop, or rather walkshop, was two-fold: to introduce participants to research practices from a range of disciplines, and to construct a field-guide to highlight ways in which Blackwattle Bay is, has, and might be, inhabited, cared for (or not) and the complex ecological and social demands this creates. To begin the walkshop, participants each shared a different method for examining place from their disciplinary field. During the twoday event, these different methods were activated through the practice of walking and were used to produce the Speculative Harbouring Field-Guide to Blackwattle Bay. In our discussion, we draw on feminist practices and politics of care, in particular, Maria Puig de la Bellacasa's articulation of "matters of care," alongside Anna Tsing's "arts of noticing" and notions of critical public pedagogy, to examine ways in which walking and reflecting can attune people to learning to care and how a field guide might facilitate such attuning.
\end{abstract}

\section{Keywords}

Field guides; care; walkshops; harbours; art

Journal of Public Pedagogies, Number 4, 2019, Guest Edited by WalkingLab: www.walkinglab.org Published by Public Pedagogies Institute: www.publicpedagogies.org Open Access article distributed under a CC-BY-NC 4.0 license 
Through this short essay we describe and reflect upon our design of a two-day interdisciplinary postgraduate walkshop-Speculative Harbouring — which took place during September 2017 in Blackwattle Bay, Sydney, Australia. The walkshop was animated around the creation of a field guide-A Speculative Field Guide to Blackwattle Bay (Johnston \& Pratt, 2017). But rather than using field guides in their traditional mode as a manual for identifying and learning about 'natural' phenomena, participants subverted the genre to publicly notice, critique, and question aspects of Blackwattle Bay and its impending redevelopment. ${ }^{i}$

In creating this event, we were guided by two key questions: "How might we better care for, and with, harbours? What modes of disciplinary and transdisciplinary practice, within and outside academia, including art and activism, might best support this care-work?" (Johnston \& Pratt, 2017, p. 5). In this text we draw out the connections between walking, noticing, field-guides, and learning to care that were facilitated by this event. As Metzger (2014) argues, "to learn to pay attention is ... fundamental to learning to care, as attention formation sensitizes us to that on which we focus our attention" (p. 1004).

In this essay, we highlight how a walkshop can be mobilised around constructing a field guide. We explicate how constructing the field guide facilitates embodied modes of learning to pay attention and learning to care, both for participants of the walkshop and future readers of the field guide. At a simplistic level, a walkshop "can be thought of as a workshop conducted through walking" (Wickson, Strand \& Kjolberg, 2015, p. 243). While walkshops can take many different forms, Wickson, Strand and Kjolberg (2015) suggest four distinguishing features: 1) discussion predominantly occurs in particular contexts while walking; 2) it has a "fluid" structure; 3) it emphasises time spent getting to know other people within the group and 4) environments are used as a means of provoking embodied multisensory "discussion and reflection" on matters of concern. It was for these reasons that we employed the walkshop format to structure day one of Speculative Harbouring and concentrated on the creation of a collective field guide during day two.

\section{Day One: Walking and Arts of Careful Noticing}

Day one of walking was framed by what Anna Tsing (2011) calls arts of noticing to direct our engagements in the field. Arts of noticing are "a way of teaching ... open yet focused attention" and can be a means of creating "passionate immersion in the lives of the nonhumans" (p. 19). For example, Tsing suggests that taxonomy is one form of noticing that draws us in particular ways to the diversity of life; likewise, poetry and painting offer different sensory engagements. While each art offers an opportunity to connect, alone they are partial, hence the importance of the plural (arts) and also our interest in and valuing of bringing an interdisciplinary team together.

Before the start of the walkshop, each participant was invited to bring a method from their respective discipline to share and use during our walks around the Bay. Through walking and trying out various methods, people's attentions were drawn to different ways of sensing the changing relationships and temporalities within this environment. Participants were also able to attend to, what the feminist philosopher Val Plumwood (2008), calls shadow places - those places that are seldom considered but "whose degradation we as commodity consumers are indirectly responsible for" (p. 147). This included reflection on seawalls, drains, plastics, persistent yet invisible pollution, colonial history, contemporary Indigenous connections to Country, and labour.

In addition to participants' contribution of methods and disciplinary expertise, we invited two field experts to walk with us in the afternoon: the Aboriginal Elder Uncle Mark, and the marine scientist Ross Coleman. Uncle Mark welcomed us to Country with a smoking 
ceremony, before leading us around the Bay and sharing insights and stories from his vast intergenerational knowledge and enduring responsibility in caring for Country (see Figure 1). Coleman described modes of seeing and experimental practice within the discipline of science by showcasing the flower pot project — an intervention on the sea walls in Blackwattle Bay. He highlighted that, since colonisation, seawalls in Sydney have been built to be flat and featureless structures, which are not ideal for sea life. The group observed how the flower pot structures soften these hard surfaces by mimicking microhabitats of rocky shores (Strain, Morris, \& Bishop, 2017).

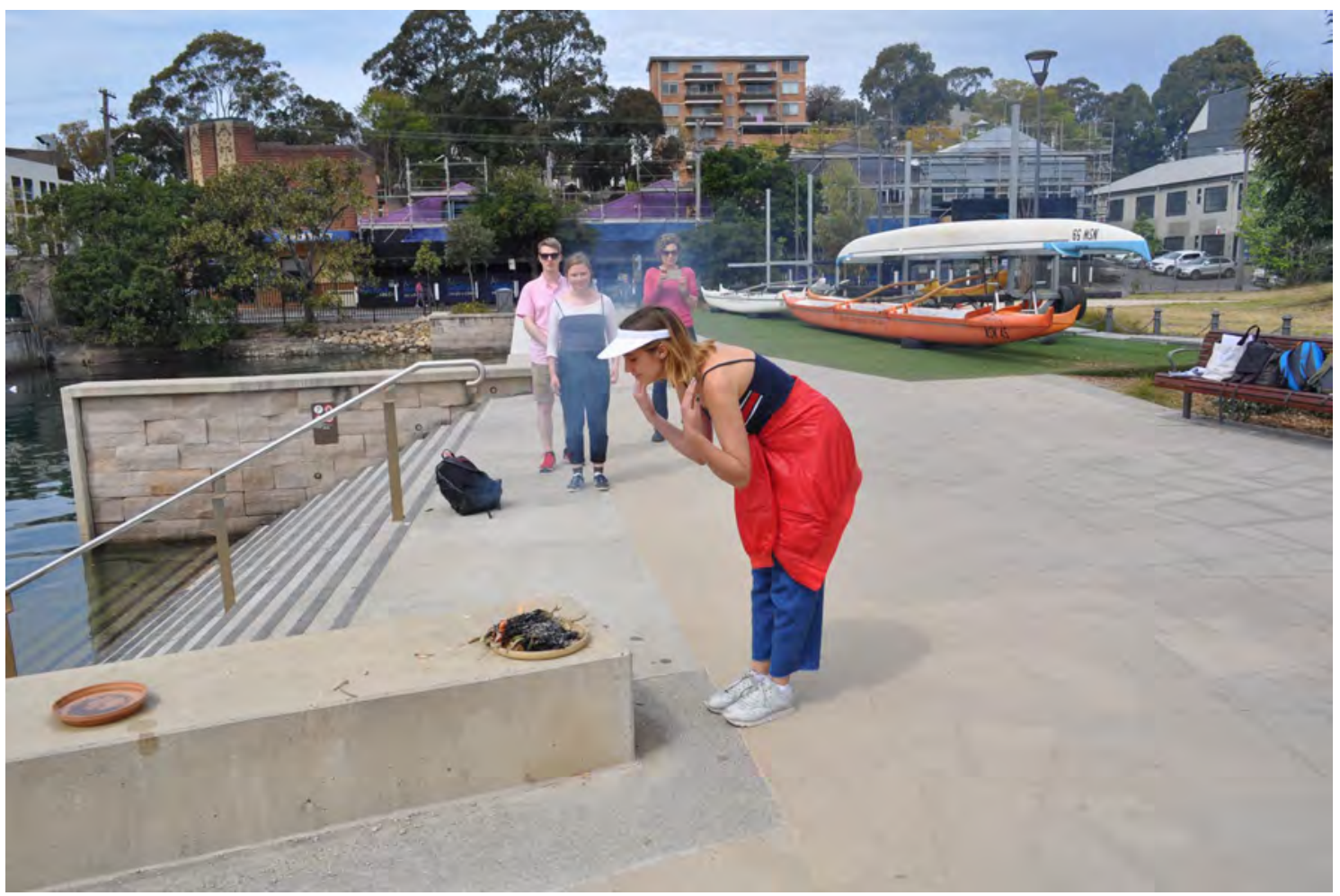

Figure 1: Welcome to Country Smoking Ceremony performed by Elder Uncle Mark during the Speculative Harbouring walkshop. Photo Credit: Kate Johnston, 2017.

As the first day drew to a close, participants were introduced to the idea of matters of care (Puig de la Bellacasa, 2011). Participants were invited to choose a particular matter that had arisen over the day, and to return to the site to further engage with their matter. According to Puig de la Bellacasa (2011), care is both "an affective state [and] a material vital doing" (p. 90). Through different forms of sensory observation, we encouraged participants to consider how noticing and learning to care, when considered as an affective state, speaks to the way caring manifests itself physically. Thinking of care as a material vital doing, is to consider care as more than simply a feeling of concern for others, but as a means of physical and material action and involvement (see Van Dooren, 2014). Writing on care, Deborah Bird Rose (2017) describes how we can be "lured" into caring relations (p. G51). She draws on and extends the concept of "shimmer" — an aboriginal aesthetic, based on the Yolngu term 'bir'yun,' that speaks to the way one can be lured into multispecies encounters through relational beauty, brilliance and motion. Rose (2017) states, an "encounter with shimmer may help us better to notice and care for those around us who are in peril" (p. G52). For example, we can be lured by the sight of fish, their scales glinting in the sun, as they feed in a working harbour such as Blackwattle Bay. 
Informed by these notions of care, we encouraged participants to translate their observations into questions and lures for the field guide; provocations that mobilised a matter of care. Care understood in this way is situated in, and arises from, relational and material practices—walking, listening, noticing, making, resisting, disrupting, shimmering - that can generate affective attachments.

\section{Day Two: Field Guides as a Medium for Careful Noticing}

Day two concentrated on representational practices and politics through the collective construction of a field guide. The group moved from walking and arts of noticing to reflect on the role a field guide could play in mobilising different ways of noticing and caring. Before creating their own field guide entries, participants were introduced to different field guides, including how they emerged out of $18^{\text {th }}$ Century botanical identification manuals in France (Scharf, 2009). Innovations in format, such as identification keys, taxonomic organisation, illustrations, and species descriptions laid the foundation for field guides to become a tool for public pedagogy that helps and unites both professionals and amateurs in the field (Farnsworth et al., 2013; Scharf, 2009).

Drawing on more contemporary examples of field guides, such as Sarah Kanouse's Postnaturalist Field Kit for Saint-Henri (2010) and Ruben Pater's Drone Survival Guide (n.d.), which both subvert the format of the field guide, participants created pages that critiqued singular dominant perspectives, including colonial narratives and objective taxonomies. For example, Natalie Pearson (2017), trained in heritage and museum studies asks: "What maritime histories can be told here? Whose stories and pasts are privileged in the telling of these maritime histories?" (p. 15). A collaborative entry to the guide from Christine Winter, Louisa King and Jakelin Troy (2017) questions: "Where does the harbour end and human start?" (p. 28) and proposes an activity inviting readers to "attune yourself to harbour's salts and minerals entering your bodies \& embedding within your bones, skin and flesh..." (p. 28). With a background in law, government and international relations, Joseph McDonald (2017) took up provocations from Uncle Mark and encouraged readers to listen to Country and reflect on Indigenous-led place-making (p. 25).

\section{Careful Noticing}

Speculative Harbouring was an experimental walkshop and what emerged was a multi-layered, interdisciplinary engagement with the senses and place. It encouraged different sensory engagements with place as well as attention to the diverse and potentially less-noticed aspects of the harbour. We especially wanted to disrupt any one disciplinary mode in order to promote careful noticing - that is, the kind of noticing that opens up possibilities of understanding, empathy and care.

Through this brief description of Speculative Harbouring, we articulate one way in which the everyday practice of walking and the popular culture format of the field guide have the potential to be forms of 'critical public pedagogy' — pedagogies which can disrupt dominant ideologies and generate counter narratives (see Giroux, 2000; Sandlin, O’Malley, \& Burdick, 2011). While our group's engagement with the Bay was brief and may not have facilitated long-term involvement, our experimentation with the field guide as a pedagogical tool for multiple publics, in conjunction with practices of walking that it animates, demonstrates the opportunity afforded by these formats to entice others to notice and care in public spaces. In our case, participants engaged with dominant ideologies of nature, progress, development, gender, class, race, and settler narratives, with the aim of generating new ways of thinking about, and possibilities for caring for, Blackwattle Bay. 


\section{References}

Farnsworth, E., Chu, M., Kress, J. W., Neill, A. K., Best, J. H., Pickering, J., ... Ellison, A. M. (2013). Next-generation field guides._BioScience, 63(11), 891-899. https://doi.org/10.1525/bio.2013.63.11.8

Giroux, H. A. (2000). Public pedagogy as cultural politics: Stuart Hall and the "crisis" of culture. Cultural Studies, 14(2), 341-360. https://doi.org/10.1080/095023800334913

Johnston, K. \& Pratt, S. (2017). Editors. Speculative Field Guide to Blackwattle Bay. Sydney, NSW: Sydney Environment Institute.

Kanouse, S. (2010). A Post-Naturalist Field Kit for Saint-Henri. Retrieved January 23, 2019, from http://readysubjects.org/portfolio/a-post-naturalist-field-kit-for-saint-henri/

McDonald, Joseph. (2017). Listening to Country. In Johnston \& Pratt (Eds.), Speculative Field Guide to Blackwattle Bay (pp. 22-25). Sydney, NSW: Sydney Environment Institute.

Metzger, J. (2014). Spatial planning and/as caring for more-than-human place. Environment and Planning A. 46(5), 1001-1011. https://doi.org/10.1068\%2Fa140086c

Pater, R. (n.d.). Drone Survival Guide. Retrieved January 23, 2019, from http://www.dronesurvivalguide.org/

Pearson, N. (2017). Preserving Our Maritime Pasts. In Johnston \& Pratt (Eds.), Speculative Field Guide to Blackwattle Bay (pp. 14-17). Sydney, NSW: Sydney Environment Institute.

Plumwood, V. (2008). Shadow places and the politics of dwelling. Australian Humanities Review, (44), 139-150.

Puig de la Bellacasa, M. (2011). Matters of care in technoscience: Assembling neglected things. Social Studies of Science, 41(1), 85-106.

https://doi.org/10.1177\%2F0306312710380301

Rose, D. B. (2017). Shimmer: When All You Love is Being Trashed. In A. Lowenhaupt Tsing, H. A. Swanson, E. Gan, and N. Bubandt (Eds.), Arts of Living on Damaged Planet: Ghosts and Monsters of the Anthropocene (pp. G51-G63). Minneapolis, MN: University of Minnesota Press.

Sandlin, J. A., O'Malley, M. P., \& Burdick, J. (2011). Mapping the complexity of public pedagogy scholarship: 1894-2010. Review of Educational Research, 81(3), 338-375. https://doi.org/10.3102\%2F0034654311413395

Scharf, S. T. (2009). Identification keys, the "natural method," and the development of plant identification manuals. Journal of the History of Biology.

42(1), 73-117. doi:10.1007/s10739-008-9161-0

Strain, E., Morris, R., \& Bishop, M. (2017). Sydney Harbour: Enhancing seawall sustainability. NSW Department of Primary Industries. Canberra, Australia.

Tsing, A. (2011). Arts of inclusion, or, how to love a mushroom. Australian Humanities Review, (50), 5-21.

Van Dooren, T. (2014). Care: Living lexicon for the environmental humanities. Environmental Humanities, 5(1), 291-294. https://doi.org/10.1215/22011919-3615541 
Wickson, F., Strand, R. \& Kjølberg, K. L. (2015). The Walkshop approach to science and technology ethics. Science and Engineering Ethics, 21(1), 241-264. doi: 10.1007/s11948$\underline{014-9526-\mathrm{z}}$

Winter, C., King, L. \& Troy, J. (2017). The Body is Harbour. In Johnston \& Pratt (Eds.), Speculative Field Guide to Blackwattle Bay (pp. 26-33). Sydney, NSW: Sydney Environment Institute.

As a researcher, educator, artist and techno-scientific muser, Susanne Pratt explores how creative practice can foster social and environmental responsibility, with an emphasis on improving environmental health and collective flourishing. She is currently based in the Faculty of Transdisciplinary Innovation, University of Technology Sydney (UTS) where she cofounded the $x$ Futures Lab.

Kate Johnson is a Postdoctoral Research Fellow on the Australian Research Council (ARC) funded project FoodLab Sydney (2018-2020), with partners including City of Sydney and FoodLab Detroit. She previously worked in the Department of Gender and Cultural Studies (University of Sydney) on the Sustainable Fish Lab project. Her research interests include environmental/food justice, food systems, sustainability, governance, blue humanities, experimental and interdisciplinary methodologies.

\footnotetext{
${ }^{\mathrm{i}}$ For more information on the Bays Precinct redevelopment see: https://www.ugdc.nsw.gov.au/growth-centres/thebays-precinct/
} 